\title{
MÉTODO DO CASO: “NÃO SEI, NÃO ...” ENFRENTANDO AS BARREIRAS \\ À IMPLANTAÇÃO DO MÉTODO
}

THE CASE METHOD: "I'M NOT SURE ..."

FACING BARRIERS TO IMPLEMENTING THE METHOD

Recebido em: 23/07/2013 Aprovado em: 12/09/2013 Avaliado pelo sistema double blind review Editora Científica: Manolita Correia Lima

\section{ROBERTA DIAS CAMPOS roberta.campos@coppead.ufrj.br VICTOR MANOEL CUNHA DE ALMEIDA}

UNIVERSIDADE FEDERAL DO RIO DE JANEIRO

\begin{abstract}
RESUMO
Este caso de ensino foi elaborado para possibilitar a discussão sobre vantagens e desvantagens da adoção de métodos de ensino centrados no aluno, com particular ênfase no método do caso. O público alvo desse caso são docentes na condição de alunos em cursos de mestrado ou doutorado, nas disciplinas de metodologia de ensino ou didática do ensino superior, bem como em cursos de extensão para formação ou aperfeiçoamento de professores. O caso apresenta o dilema vivido por Cosmo, jovem professor recém-contratado pelo IESG (Instituto de Educação Superior em Gestão), que deseja adotar o método do caso como prática docente em um ambiente institucional com experiências didáticas distintas e heterogêneas. Apresenta também a visão de diversos atores da instituição, discutindo o desafio em harmonizar a estratégia didática da instituição e a prática individual e cultural de seus profissionais. O caso busca estimular a reflexão sobre as barreiras e ações necessárias à adoção institucional do método do caso, refletidas em três níveis da organização: o corpo docente, o corpo discente e o conjunto da estrutura institucional.

Palavras-chave: caso de ensino; método do caso, didática de ensino; pós-graduação; método ativo de ensino.
\end{abstract}

\begin{abstract}
This teaching case was designed to enable discussion on the pros and cons of adopting student-centered methods of teaching, with particular emphasis on the case method. The target audience comprises teachers undertaking Master's or doctoral degrees in teaching methodology and higher education didactics, as well as training and development extension courses for teachers. It presents the dilemma experienced by Cosmo, a young professor recently hired by the IESG (Institute of Higher Education in Management), who wishes to adopt the case method as a teaching practice within an institutional setting and with distinct and heterogeneous didactic experiences. It also presents the views of different stakeholders in the institution, discussing the challenge to accommodate its teaching strategy with its professionals' individual and cultural daily practice. The case intends to foster reflection on the barriers and actions required for institutional case method adoption, seen from three of the organization's levels: the faculty, the student body and the institutional structure as a whole.

Keywords: teaching case; case method; didactics; graduate course; active teaching method.
\end{abstract}




\section{INTRODUÇÃO}

Cosmo lembrava o dia em que chegara ao Instituto de Educação Superior em Gestão (IESG) em seu primeiro dia de trabalho e pensara: como serão os alunos aqui? Sua experiência docente não era longa, mas vinha de uma significativa experiência como professor assistente em uma universidade norte-americana, onde trabalhou durante cinco anos depois de ter concluído seu doutorado.

Enquanto saboreava um café na sala de professores do IESG, Cosmo relia pela terceira vez a sua primeira avaliação em um curso no IESG. Os comentários não foram exatamente os esperados e ele refletia profundamente sobre sua missão naquele instituto.

Uma aluna comentou de forma bem assertiva:

O conteúdo abordado não foi capaz de motivar a turma. Um dos casos estudados em aula já tinha sido estudado por outro professor em período anterior. Os professores precisam se comunicar mais.

Outro aluno comentou:

O professor estimula a discussão prática de empresas reais, porém acho que seria importante tentar substituir o excesso de casos. Temos coisas mais importantes para aprender. Essa é a terceira matéria que usa casos. Já não acrescenta mais nada! Passamos muito tempo lendo casos quando poderíamos estar lendo livros!

Seu alento veio de alguns comentários positivos aqui e ali:

Esse foi um curso muito diferente; me senti na hora da verdade, pensando na prática como as coisas acontecem. Gostei muito dessa coisa de método do caso! Bem melhor do que ficar fazendo fichamentos mecânicos. Aqui estudamos a vida real!

Cosmo olhou novamente seu programa montado exclusivamente baseado na metodologia do caso e perguntava-se o que fazer daqui para frente. Deveria insistir no uso do método do caso como conhecera nos EUA? Ou deveria se ajustar às práticas de ensino do IESG? 


\section{ANTECEDENTES}

Cosmo chegara ao IESG seis meses antes, após um período de cinco anos dando aulas em uma faculdade americana que usava o método de casos de forma sistemática.

Aprendera a elaborar o programa de seus cursos de acordo com o paradigma de aprendizagem centrada no participante, principalmente mediante o uso de casos de ensino para discutir sobre a tomada de decisão. Acreditava que o uso de casos incentivava a identificação indutiva de conceitos teóricos, aplicáveis em cada situação.

Em seu íntimo, essa era a melhor forma de ensinar no campo de negócios, pois acreditava que as aulas puramente expositivas não eram capazes de capturar a atenção do aluno, resultando em uma retenção baixa dos conceitos.

Lembrava-se inclusive de seu primeiro dia de aula como aluno na mesma faculdade americana, quando teve que frequentar as aulas com a turma de мва. Sua formação no Brasil tinha sido em um mestrado acadêmico com aulas expositivas e de debate teórico, e pouco recurso ao caso. Para a primeira aula de мва como aluno, ele leu um caso bastante envolvente sobre um executivo da Disney que precisava tomar uma decisão. Ao terminar a leitura, perguntou-se como o professor retiraria conceitos teóricos daquela situação. Disse para si mesmo: "Essa aula vai acabar em um grande bate-papo, repleto de opiniões!".

Todavia, surpreendeu-se com uma turma muito bem preparada, debatendo vigorosamente, respeitando certa dinâmica de discussão do caso. Professor e alunos conheciam seus papéis e sabiam como atuar nesta plenária. A discussão foi crescendo, tornando-se mais complexa, profunda; e o professor estabelecia momentos de pausa em que trazia conceitos teóricos que contribuíam para melhor entender o que estava em jogo na decisão a ser tomada. Cosmo lembrou-se que neste dia aprendeu o conceito de segmentação de mercado e toda a complexidade de sua aplicação em um caso prático.

Quando começou a dar aulas na mesma faculdade, investiu bastante tempo montando seus programas. Era difícil encontrar o caso que pudesse suscitar no debate em aula exatamente os conceitos relevantes a fim 
de cumprir o programa de curso. A escola americana dispunha de um departamento especializado na redação de casos, que gerenciava seu uso, produção e publicação. Assim, o trabalho de Cosmo, apesar de desafiador, era simplificado pela infraestrutura oferecida pela escola.

Em algumas situações, recorreu à redação de casos de próprio punho. Recolhia os dados na internet, revistas e leituras diversas, sentava-se em seu escritório e soltava a imaginação. Apesar de não serem casos reais ${ }^{1}$, na opinião de Cosmo, definitivamente eles não eram ruins. Poderiam ter uma aplicação interessante em aula. E muitas vezes ajudavam a suprir aqueles momentos do curso em que nenhum caso real se encaixava.

\section{INICIANDO NO IESG}

Após quase dez anos morando nos EuA, entre doutorado e prática docente, Cosmo resolve retornar ao Brasil. Estava ávido para difundir o que aprendera. Cosmo estava convencido de que cada vez mais, os brasileiros se confrontariam, no universo empresarial, com outros padrões culturais de gestão e era preciso estar preparado. Entendia, portanto, que o desenvolvimento do método do caso no Brasil poderia beneficiar os empresários e executivos brasileiros que se preparariam para uma tomada de decisão mais analítica, argumentada e construída por meio do debate.

Recebeu convite de algumas escolas, mas optou por instalar-se no Rio de Janeiro, sua cidade natal, e trabalhar nos cursos de pós-graduação do IESG. Foi particularmente atraído pelo fato do instituto ter uma central de casos e por buscar, por meio de sua diretoria, a maior aplicação do método por seus professores.

No entanto, apesar da forte intenção do IESG em utilizar o método do caso, Cosmo foi pouco a pouco se deparando com as dificuldades cotidianas para utilizar o método na forma em que estava acostumado nos EUA. Sua primeira iniciativa foi consultar os casos disponíveis na central de casos do IESG.

Havia muito material ali, todavia, a maior parte dos casos disponíveis apresentava-se no formato de caso-demonstração². Para surpresa de Cosmo, poucos casos disponíveis eram apresentados no formato de caso-problema ${ }^{3} \mathrm{e}$ destes, apenas alguns eram acompanhados das notas de ensino. 


\section{CENTRAL DE CASOS DO IESG}

Preocupado, Cosmo decidiu então procurar Amélia, professora do instituto e coordenadora da central de casos do IESG no RJ, para conversar sobre a questão.

Amélia recebeu-o com gentileza e disponibilidade. Ela mesma era fã e partidária do método do caso, mas admitia que muito trabalho ainda teria que ser feito na IESG. Ela inclusive percebia Cosmo como um importante elemento nesta mudança de cultura. Cosmo compartilhou sua preocupação com Amélia a respeito da indisponibilidade de casos no formato que estava acostumado nos EUA.

Amélia contemporizou:

É importante você entender, Cosmo, que estamos no meio de um processo de mudança de longo prazo. No início do IESG no Rio, o presidente da época era partidário do caso-demonstração. Quando se fundou a central de casos em parceria com a Revista Exame, o objetivo era aproveitar as informações obtidas pela revista para produção de casos para fins didáticos. Porém, esse convênio acabou imprimindo um caráter jornalístico aos casos produzidos. Para o diretor da época, essa prática fazia sentido, pois ele tinha uma cultura do caso tipo "best practices”, que conta uma história de uma decisão já tomada. Entende?

Cosmo questionou sobre o processo de mudança:

Mas como isso foi se modificando? Pois hoje na central de casos encontrei vários tipos de casos diferentes. Casos na terceira pessoa, casos na primeira pessoa, casos-demonstração, casos abertos.

Amélia continuou:

Isso revela esse momento de transição que explicava a você. Com a chegada do diretor geral atual há seis anos e com a minha chegada à área de Marketing, iniciou-se um trabalho grande de revisão metodológica. Na época, eu estava fazendo o doutorado e cursei uma disciplina especializada em método do caso. Eu e o diretor então resolvemos trazer a metodologia para o instituto. Convidamos inclusive um professor experiente no método do caso que realizou dois treinamentos para professores da graduação, um para aplicação 
e outro para a redação de casos. Depois dessas iniciativas, os professores mostraram maior entusiasmo para utilizar os casos, mas ainda havia confusão, pois a central ainda disponibilizava muitos casos do tipo caso-demonstração. Amélia explicou ainda que, logo depois do treinamento, reuniu-se com o professor coordenador da central de casos nacional do IESG com a finalidade de constituir um grupo de trabalho das três filiais para facilitar a implantação do método do caso. O grupo de trabalho decidiu não abandonar o que já havia sido feito, pois considerou o caso-demonstração importante para a graduação ${ }^{4}$, todavia, um esforço foi feito para incentivar a produção de casos-problema (no estilo de Harvard, conforme eram referidos por muitos professores).

Amélia comentou sobre as iniciativas:

A ideia do grupo era estimular a produção em quantidade, para em um segundo momento trabalhar a qualidade, ordenando e triando os casos de ensino por tipo [formato], área de conhecimento e assunto. Isso se mostrou um grande desafio. De qualquer forma, o grupo de trabalho conseguiu colocar em prática uma série de iniciativas fundamentais para a mudança de cultura: os professores foram treinados no método do caso e conseguimos aprovar com a presidência uma gratificação para a produção de casos.

Cosmo deixou a sala de Amélia dividido. Entendera que havia uma clara intenção de adoção do método do caso, mas, começava a perceber as dificuldades institucionais para operacionalização dessa política. Resolveu então procurar Álvaro, o diretor da pós-graduação. Queria saber como este via as questões de metodologia.

\section{MÉTODOS ATIVOS DE APRENDIZAGEM NO IESG}

Álvaro recebeu Cosmo, logo na manhã do dia seguinte. Ratificou o propósito do IESG de incentivar os professores na utilização de métodos centrados no aluno, tanto o método do caso, quanto outras modalidades, como exercícios em grupo, visitas a empresas, vivências, jogos de empresas e role-playing. Realçou ainda o caráter ativo do trabalho final dos alunos do IESG:

O PCA ${ }^{5}$ é praticamente um caso aberto que os alunos precisam construir do zero. Eles escolhem uma empresa real e desenvolvem um profundo trabalho 
de diagnóstico e proposta de plano de ação. Nosso objetivo é que os alunos sejam estimulados a pensar estrategicamente, criando o hábito de estudo contínuo, aprendendo a trabalhar de maneira integrada com demais alunos e com o professor orientador.

Álvaro explicou ainda sobre o alinhamento do sistema de avaliação:

Queremos que a metodologia seja nosso diferencial, um elemento de encantamento do aluno. Um exemplo dessa intenção de desenvolver uma metodologia mais ativa é nossa recomendação de distribuição dos pontos na avaliação. Hoje recomendamos que 20 a $30 \%$ da nota sejam referentes ao produto gerado pelo aluno (provas, trabalhos individuais) e 70 a $80 \%$ sejam processo, traduzindo sua participação ativa no curso, seja realizando leituras e gerando questões de discussão, seja mantendo sua presença e pontualidade, seja por sua participação ativa e construtiva em sala de aula.

O diretor da pós-graduação reconhecia os esforços da diretoria e de professores interessados na implantação do método do caso. Todavia, não ignorava os muitos desafios e obstáculos que ainda teriam de ser superados: Sei que apesar de muitos professores já programarem casos de ensino em algumas aulas, a grande maioria ainda não conseguiu utilizar o método regularmente, seja por dificuldade de aderir a uma mudança de cultura, seja por certas dificuldades que temos hoje e precisamos superar. Temos salas de aulas tradicionais, mais adaptadas à aula expositiva que à plenária de debate como sugere o método do caso. Mas nossas turmas não são grandes, temos entre 25 e 35 alunos, então conseguimos usar esse espaço, de forma adaptada. Outro ponto é que como temos projetor em todas as salas, acaba sendo mais cômodo trazermos nossos slides e darmos uma aula convencional. Além disso, alguns professores acreditam que aulas com discussão de casos aumentam a dificuldade de controle da turma.

Cosmo aproveitou para reafirmar suas crenças nas vantagens do método:

É verdade, no início eu tinha uma sensação de menor controle da turma, mas acredito que podemos avançar em termos de retenção e aprendizado se encontramos uma turma preparada e disposta. Pelo menos essa é a minha aposta. Sempre que utilizo um caso e peço aos alunos que se preparem previamente e me entreguem por escrito a preparação individual, sou 
procurado no final da aula de debate do caso por alunos preocupados com a correção. Após o debate, as possibilidades de análise do caso se multiplicaram a tal grau que eles têm a sensação de que a análise individual foi mal feita. Gosto quando isso acontece, pois é sinal de que o aprendizado desses alunos cresceu com a discussão.

Álvaro compartilhou sua percepção de que muitos alunos reagem ao método simplesmente porque são comodistas e não estão acostumados a essa dinâmica de preparação individual prévia. Para esses alunos, o professor não estaria cumprindo o seu papel de "dar aula". O diretor realçou então a importância da preparação do próprio professor para a discussão dos casos e manifestou sua preocupação em relação à disponibilidade de casos: Um problema para mim hoje é a disponibilidade de casos. A central de casos tem feito um trabalho interessante, mas por vezes os casos são um pouco longos, tanto para o tempo de leitura e preparação individual dos alunos, quanto para o tempo de sala de aula de que os professores dispõem. Talvez a central precise de mais dinamismo, desenvolver casos de vários tamanhos. Hoje temos algumas centenas de casos, precisaríamos de muitos mais.

Ocorre que tipicamente nossos professores já têm trabalho demais. Eles dão aula na pós e na graduação, muitos exercem funções executivas além das aulas. Só resta o final de semana para fazer esse tipo de atividade. Fico um pouco cético. Será que os professores vão encontrar motivação e tempo para elaborar seus próprios casos?

Cosmo ficou com a sensação de que a reunião foi encerrada no melhor estilo do encerramento de uma discussão de caso - com uma questão em aberto.

\section{PÓS-GRADUAÇÃO NO IESG}

As instalações da pós-graduação do IESG são novas, bem-cuidadas e organizadas. As salas são bem iluminadas, com ar condicionado e equipadas com computador, telão, projetor e caixas de som. O quadro branco não é muito grande, mas o professor pode pedir à secretaria folhas de flip chart. Nas salas, as plaquinhas com nomes não são utilizadas pelos alunos, pois escorregam das mesas inclinadas. Os professores precisam decorar o nome dos alunos para a interação e atribuição de notas de participação. 
O formato da sala é típico para uma aula expositiva, com todos os alunos sentados voltados para o quadro. Cosmo acreditava que para o método do caso, o ideal era uma sala em forma de anfiteatro em $U$, facilitando a discussão entre alunos. Porém, as cadeiras e mesas são fixas, impedindo a remodelação da aula para formatos diversos, tais como pequenos grupos ou círculos para debate. $\mathrm{O}$ instituto também não dispõe de salas menores para a realização de discussão em pequenos grupos.

O aluno da pós-graduação do IESG tem um perfil bem definido. São pessoas de classes médias altas (A e B) que podem arcar com os custos de um curso em uma instituição privada. Normalmente, os próprios alunos (ou sua família) custeiam sua formação. Em sua maioria, moram na zona sul do Rio de Janeiro, Barra ou Niterói e são formados ou trabalham nas áreas de administração e comunicação. Buscam ampliar suas chances de sucesso profissional, melhorando seu currículo com um curso de pós-graduação em uma instituição reconhecida pelo mercado.

Os cursos da pós-graduação acontecem à noite ou de manhã e contam com disciplinas que variam de seis a onze encontros semanais de uma hora e quarenta minutos cada. Na maior parte, os alunos alegam ter pouco tempo para estudar. Tipicamente dispõem apenas de seu tempo no final de semana para estudar para as aulas.

\section{PRIMEIRA AULA NA PÓS-GRADUAÇÃO DA IESG}

Antes de começar seu primeiro curso na pós-graduação, Cosmo realizou uma longa preparação. A montagem do programa exigiu um longo tempo de estudo de cada caso para verificar sua adequação à temática do programa. Analisou ainda o tamanho do caso, pois o debate em pequenos grupos e em plenária deveria ocorrer em uma aula de menos de duas horas. Imaginava que casos muito extensos não seriam lidos nem preparados com cuidado.

A grande dificuldade de Cosmo, no entanto, foi com a obtenção de casos. Alocar um caso por sessão é uma tarefa complexa. A princípio, pensou em escolher casos estrangeiros, traduzi-los e pagar os direitos de uso. Mas além do custo alto, essa opção tomaria tempo. Preocupava também o fato de que os alunos poderiam se ressentir de só ver casos estrangeiros. 
Cosmo analisou vários casos da central de casos do IESG e adaptou alguns deles para o formato de caso-problema, realçando um protagonista que estaria na posição de tomador de decisão com quem os alunos poderiam se identificar. Não sabia se podia fazer isso, mas, por fazer parte do quadro de professores do instituto, imaginava que não haveria problema.

Iniciou também uma série de contatos com amigos, empresários e executivos, para tentar redigir seus próprios casos. Todavia, sabia que isso seria um trabalho de mais longo prazo. Adicionalmente, essa produção poderia render uma boa gratificação se fosse submetida à central de casos. Contudo se perguntava se deveria submeter seus casos à central, pois por outro lado, nada garantiria que seus casos não seriam usados em outros cursos por outros professores, gerando repetição e insatisfação junto aos alunos. Esse controle não existia.

Solicitou à secretaria de professores uma lista com o nome dos alunos e informações de perfil. Encontrou uma equipe gentil, trabalhadora e disponível. Todo o material era disponibilizado aos alunos com antecedência, encadernado com o programa, os slides impressos e os materiais de leitura. No início do curso, todos os alunos dispunham de todos os casos a serem preparados e dos artigos para leitura prévia.

Na primeira aula apresentou seu programa e conversou com a turma para conhecê-los melhor. Lembrou sobre a importância da boa preparação individual prévia dos casos. Os alunos pareceram entusiasmados, curiosos. Cosmo precisou desde a primeira aula fazer um grande esforço para memorizar os nomes dos alunos. Felizmente as turmas não excediam 30 alunos. Isso era vital para o sistema de avaliação definido com base na participação com qualidade e na preparação individual do caso.

Para facilitar o processo de avaliação, ele recorreu a um processo usado na sua escola norte-americana. Desenhou um mapa da sala e anotou o nome dos alunos que se sentavam em cada lugar. Avisou à turma que dali em diante aqueles eram seus lugares obrigatórios, pois a nota de participação seria dada com base no mapa da sala.

Um dos alunos levantou a mão e perguntou: "Vamos ter que sentar assim em todas as aulas. Isso é novidade aqui no IESG?". Cosmo explicou: 
Não, será apenas na minha aula. Como expliquei a vocês, essa aula é baseada no debate ativo em sala e a participação é fundamental. Para que eu possa dar notas com maior justiça é importante que eu saiba exatamente a quem eu estarei atribuindo os pontos.

$\mathrm{O}$ aluno se calou pensativo.

Cosmo tomou a palavra e fez uma breve apresentação sobre o programa da sua disciplina de Marketing e discutiu os temas das aulas a seguir. Detevese com mais detalhe no caso programado para a aula seguinte. Após a aula encerrada, enquanto Cosmo reunia seu material e desligava o computador, Pedro, um aluno que se manteve calado a aula toda, aproximou-se de sua mesa e manifestou sua preocupação:

Professor! ... Será que isso vai dar certo? Essa coisa de ter muita nota de participação. Vai ficar todo mundo falando qualquer coisa para ganhar pontos. Vai ser uma batalha. Como ficam os mais tímidos? Eu não sei se vou me dar bem na sua disciplina.

Cosmo surpreendeu-se com a abordagem assertiva de Pedro. Respirou fundo e argumentou:

Pedro, o que importa é a participação com qualidade, que traga contribuições ao debate e aos colegas. Repetir os dados do caso ou coisas que os outros disseram, por exemplo, dizer algo só por dizer, não vai refletir em uma melhor nota. Além disso, se você sente que será mais desafiador para você participar de uma aula neste formato, podemos pensar juntos em algumas formas de facilitar a sua participação. Mas acho que você não deveria perder a oportunidade de participar do debate, pois permitirá o desenvolvimento de habilidades essenciais a um bom executivo. Por exemplo, você gostaria de abrir a discussão da aula que vem? Você pode fazer um breve resumo de seu ponto de vista sobre o caso, mas não precisa, em um primeiro momento, se lançar na briga pela palavra. Pelo menos até você se acostumar com a dinâmica. O que você acha?

Pedro balançou a cabeça como quem está pensando "não sei, não”. Cosmo despediu-se do aluno refletindo: "será que os alunos saberão distinguir a boa participação da má? Será que precisarei explicar até isso?”. 


\section{SEGUNDA AULA NA PÓS-GRADUAÇÃO DA IESG}

$\mathrm{Na}$ segunda aula, Cosmo chegou animado para vivenciar seu primeiro debate. Realizou a chamada com base nos locais ocupados ou vagos em seu mapa da sala. Recapitulou o que havia sido dito na aula anterior e apresentou o plano da aula. Os alunos deveriam discutir em pequenos grupos para depois participarem da discussão plenária. Para facilitar, Cosmo resolveu colocar no quadro algumas questões de orientação:

- Qual é o problema da empresa?

- Quais alternativas vocês propõem?

- Quais critérios devemos utilizar para avaliar as alternativas?

- Quais alternativas vocês recomendam?

- Como a alternativa deve ser implantada?

Cosmo dividiu a turma em grupos de cinco alunos no próprio espaço da sala de aula. A discussão transcorreu sem maiores problemas. Os alunos pareciam animados, discutindo e trocando ideias. Cosmo percebeu uma tendência geral na forma de trabalhar dos grupos: certa desordem. Os alunos não se preocupavam com o tempo ou com a resposta a todas as questões. Perdiam tempo demais em algumas questões e eram mais superficiais em outras. Alguns grupos passaram quase todo o tempo tentando definir o problema da empresa. Cosmo percebeu que isso se devia muito ao fato de que todos os grupos tentavam chegar a um consenso. Por essa razão a discussão em alguns grupos não avançava.

Quando reuniu a turma para a discussão plenária percebeu que tinha um grupo com preparação desigual. Em sua maioria, a leitura individual prévia do caso havia sido feita, mas o aprofundamento da análise não tinha sido uniforme. Além disso, na discussão, todos tentavam falar ao mesmo tempo, realizavam conversas em paralelo, interrompiam-se uns aos outros. A motivação parecia ser grande, mas o grupo era bastante inexperiente em conduzir como grupo um debate de caso. No final, Cosmo percebeu em alguns alunos os semblantes iluminados, dispostos e animados. Em outros, a expressão de dúvida e confusão.

Cosmo encerrou a aula dez minutos mais cedo e perguntou: "Quantos de vocês já haviam participado de uma aula desse tipo?”. Cinco alunos 
levantaram a mão. Ele se dirigiu a um deles e pediu para que o aluno relatasse sobre a experiência prévia.

Na graduação eu tinha um professor que usava casos e também tive uma professora que sempre fazia dinâmicas. Tínhamos que realizar jogos, gincanas. Aulas mais participativas.

Cosmo ouviu com atenção. Agradeceu aos alunos e pediu que cada um colocasse em uma folha de papel o que tinha achado daquela aula. Recolheu os papéis, agradeceu e dispensou a turma. Olhou para aqueles papéis e ficou se perguntando o que leria ali.

\section{CONVERSA NA SALA DOS PROFESSORES}

Ao longo de suas primeiras semanas dando aula na pós-graduação, Cosmo conheceu na sala dos professores alguns de seus colegas do IESG. Esse contato foi bastante proveitoso, pois pôde trocar experiências e impressões. Seu principal colega era Jorge, que dava aulas no mesmo horário de Cosmo.

A principal dúvida de Cosmo era sobre a obtenção de casos. Como os outros professores faziam? Jorge explicou com naturalidade:

Uso casinhos pequenos que retiro de livros, como aqueles do Kotler ou de outros autores. São bons para ilustrar os conceitos que estamos apresentando. Em uma aula típica, reunindo todos os casinhos que eu uso, gasto em média uns 30 minutos distribuídos ao longo de quase duas horas. O grosso do tempo eu uso para apresentar conceitos no PowerPoint; os casos são bons para fixar depois. Tem casos ótimos, posso mostrar para você depois.

Cosmo decidiu compartilhar com Jorge suas primeiras impressões:

Na aula passada, realizei minha primeira discussão de caso. Sabe como é? Usando o método do caso, com discussão em grupos e depois plenária. Acontece que a reação da turma foi muito diferente do que eu esperava. No final da aula pedi para todos colocarem suas impressões em uma folha de papel e tive um resultado muito dividido. Uma parte da turma gostou da aula. Achou dinâmica, divertida, podendo ser apenas um pouco mais ordenada. Mas ... outros alunos, quase metade, disseram que era perda de tempo. Para eles, preciso dar aulas expositivas, de conceitos, palestrando. Um deles me perguntou se eu não ia usar PowerPoint como os outros professores! Fiquei me perguntando se os alunos compreendem o método do caso. 
Ao saber que Cosmo havia dedicado uma hora e vinte minutos para a discussão do caso, Jorge manifestou certo incômodo: “Tudo isso! Mas como você pretende passar o programa? O programa dessa disciplina de Marketing é muito extenso!". Foi difícil para Cosmo esconder a reação de surpresa à pergunta do colega, mas tentou explicar:

Acontece que no método do caso os conceitos vão "surgindo" ao longo da preparação individual e da discussão. Na aula passada usei um caso que deveria possibilitar a indução dos conceitos de segmentação e de posicionamento.

Jorge sentenciou: "Pois é, deveria ... mas a questão é que parece que isso não funcionou para todos os alunos, não é mesmo?”. Seguiu-se um silêncio embaraçador que foi quebrado pelo próprio Jorge:

Talvez os alunos não estejam realmente preparados para o método do caso. Nós fomos muito bem treinados no método, mas os alunos não receberam o mesmo treinamento. Inclusive existe uma apostila muito boa, redigida pela direção acadêmica sobre o método do caso. Posso enviá-la para você.

Cosmo ficou perplexo com o comentário, pois se era fato que Jorge havia sido muito bem treinado no método, por que ele havia decidido não utilizá-lo? Não foi necessário verbalizar a pergunta. Jorge emendou logo uma mea culpa:

Vejo dois problemas para utilizar o método assim de forma mais ortodoxa. Em primeiro lugar é a indisponibilidade de casos. Acaba tendo pouco caso para muita gente e corremos o risco de repetir casos. O pessoal da secretaria até nos avisa informalmente - quando eles notam - se isso acontece, mas não há um controle formal. Em segundo lugar, acho difícil achar casos que casem exatamente com os temas que precisamos abordar. Então, eu, por exemplo, dou aulas mais expositivas, com casinhos para exemplo e fixação, e no final do curso, na última aula, dou um caso maior, mais aprofundado e faço uma discussão seguindo o método. Também acho que dar aula só com casos é mais difícil, sendo sincero, parece que perco o controle da turma ou do programa. Então acabo fazendo isso. Usando mais os casos menores e o caso grande só no final.

A conversa terminou com uma sugestão de Jorge:

Por que você não dá um passo atrás e explica aos alunos o que é o método do caso? Posso conseguir os slides do nosso treinamento. Talvez fique mais claro o que é esperado deles. 


\section{O CONVITE PARA O SEMESTRE SEGUINTE}

Cosmo olhava pensativo o convite de Álvaro para continuar lecionando o curso de Marketing no semestre seguinte. Na semana anterior eles haviam tido uma reunião. Cosmo apresentou sua proposta de curso e relatou as dificuldades que estava enfrentando e suas propostas de adaptações para continuar usando o método do caso. Essa reunião foi convocada pelo diretor da pós-graduação após uma avaliação dividida. O IEsG decidiu apostar em Cosmo, afinal seu currículo era invejável, mas era preciso melhorar o nível de satisfação dos alunos.

O primeiro impulso de Cosmo era lutar pelo método do caso até onde fosse possível. Planejava treinar os alunos em um módulo gratuito na pós-graduação, na primeira semana de aula. Queria proporcionar mais qualidade ao debate. Estava também animado para produzir mais casos brasileiros, mas sabia que não conseguiria produzir muita coisa de imediato.

No fundo questionava se estava no caminho certo. O método seria adequado à realidade do IESG e, sobretudo, às necessidades do aluno deste instituto? Por que esse método seria melhor? Na perspectiva de quem? Não seria esforço demais entrar nessa batalha? Cosmo sentia-se em uma espécie de cruzada pelo método, contando com alguns aliados, mas enfrentando muita adversidade. No final do dia os resultados valeriam a pena?

E se continuasse obtendo avaliações ruins? Isso poderia afetar a sua carreira como professor. Cosmo temia por seu futuro ali. Será que não deveria aprender um pouquinho de PowerPoint e utilizar mais casosdemonstração, mesclando as duas abordagens como fazia Jorge? Afinal, um pensamento não saia de sua mente: Jorge era bastante experiente e pertencia ao seleto grupo dos professores melhor avaliados do IESG.

Cosmo decidiu aceitar o convite para continuar lecionando o curso de Marketing no semestre seguinte, mas ainda não havia decidido que professor ele seria no próximo módulo. 
1 Esse tipo de caso é conhecido como "armchair". Tipicamente o(s) autor(es) elabora(m) o caso com base em informações coletadas em suas pesquisas acadêmicas ou experiências com serviços de consultoria.

2 O caso-demonstração geralmente apresenta a análise do(s) autor(es) no corpo da descrição do caso, sendo usado tipicamente para ilustrar aulas expositivas.

3 Formato de caso concebido e popularizado na Universidade de Harvard. Apresenta apenas o dilema do gestor, acompanhado de informações sobre a situação e sobre a empresa, cabendo à turma debater os caminhos a seguir.

4 É importante notar que a operação da graduação correspondia à grande parte da receita do IESG até então.

5 PCA - Projeto de Conclusão Acadêmico: trata-se do projeto final de análise e consultoria tomando por base uma empresa real. O trabalho é sempre orientado por um professor de Marketing ou Estratégia. 


\section{NOTAS DE ENSINO}

\section{OBJETIVOS DE APRENDIZAGEM}

O caso de ensino IEsG foi elaborado para possibilitar a discussão sobre as vantagens e desvantagens da adoção de métodos de ensino centrados no aluno, com particular ênfase no método do caso. O método do caso se faz relevante na prática docente na área de administração principalmente porque é capaz de promover o desenvolvimento de habilidades de análise e pensamento crítico, tomada de decisão, julgamento entre distintos cursos de ação, elaboração de pressupostos e inferências, apresentação de pontos de vista, escuta ativa, entendimento da perspectiva do outro, bem como de conectar a teoria à prática (HEATH, 2006). O público alvo desse caso, portanto, são docentes ou futuros docentes na condição de alunos em cursos de mestrado ou doutorado, nas disciplinas de metodologia de ensino ou didática do ensino superior. $O$ caso pode servir de estímulo a uma discussão de abertura (ou encerramento) da disciplina, convidando a uma reflexão sistêmica da adoção do método, entendendo suas prerrogativas estruturais, institucionais e culturais. Alternativamente, pode ser usado em treinamentos internos de professores, em programas de graduação e pós-graduação (lato $e$ stricto sensu) que desejem adotar o método do caso como ferramenta didática.

Ao final da discussão do caso de ensino, espera-se que os alunos possam identificar: (a) As principais habilidades e características necessárias ao docente que deseja adotar uma prática didática centrada no aluno; (b) Aspectos do perfil e da disposição do corpo discente que são requisitos à adoção ajustada do método do caso; (c) Condições, processos e disposições institucionais que condicionam a fluida adoção de métodos de ensino centrados no aluno.

Adicionalmente, o aprendizado com base na aplicação deste caso deverá mobilizar três níveis de aprendizado, com conteúdos específicos:

- Aprendizado conceitual: os participantes poderão ampliar seu conhecimento sobre o método do caso, por meio da construção indutiva dos elementos centrais ao bom funcionamento da metodologia e à ampliação da qualidade do aprendizado pelos alunos. Conhecerão 
também conceitos relacionados à prática da metodologia como o aprendizado indutivo, o caso aberto versus o caso exemplo e as condições físicas de sala de aula para aprendizado do mesmo;

- Construção de habilidades: o método do caso estimula e desenvolve a habilidade de tomada de decisão. Neste caso, espera-se que os professores discutam sua opção metodológica e tenham mais clareza do impacto e das características da opção que fazem em termos da metodologia que utilizam em seu cotidiano. Esta conscientização passa pela decisão de um método adaptado à realidade da escola estudada, entendendo os pontos positivos e negativos implicados em cada um dos caminhos metodológicos que podem ser tomados (aula expositiva versus aula com método do caso);

- Desenvolvimento atitudinal: desenvolver na equipe de professores o senso de responsabilidade pela aprendizagem ativa e pelo funcionamento do método, mediante a produção autônoma de novos casos, reduzindo a condução das aulas, dando mais espaço ao aluno no espaço da aula, compondo programas baseados na mentalidade de aprendizagem indutiva centrada no aluno.

\section{PROTAGONISTA E FONTES DE INFORMAÇÃO}

O caso é apresentado sob o ponto de vista de Cosmo, jovem professor recémcontratado pelo IESG (Instituto de Educação Superior em Gestão), após cinco anos de experiência docente como professor assistente em uma universidade americana, onde Cosmo também cursou o doutorado. O caso é fruto de um dilema real, vivido por um professor em uma instituição de ensino do Rio de Janeiro. Foram realizadas entrevistas com outros professores do IESG, com o diretor da pós-graduação lato sensu, e com a coordenadora da central de casos da filial. Tanto a instituição como seus profissionais tiveram seus nomes disfarçados para confecção deste caso. Os autores do caso puderam ainda visitar as instalações da instituição (salas de aula, sala de professores, secretaria) tanto para a pós-graduação quanto graduação. E tiveram acesso a documentos como programas de disciplinas, arquivos utilizados em treinamentos de método do caso, exemplos de casos da central de casos, e avaliações discentes. 


\section{PLANO DE ENSINO}

O tempo total necessário para a sessão plenária pode variar entre 50 e 80 minutos, dependendo da distribuição típica de horários de aula da instituição de ensino. A abertura da discussão em plenária - lâmina I do quadro proposto deve exigir $15 / 20$ minutos. A análise das questões do caso - lâmina 2 do quadro proposto deve consumir $30 / 50$ minutos. O encerramento da discussão plenária ocupará os 5 / io minutos restantes - lâmina 3 do quadro proposto (vide Apêndice A).

\section{TÉCNICAS DIDÁTICAS}

O caso foi desenvolvido pressupondo a preparação individual prévia dos alunos. Para este caso, sugere-se que a preparação prévia do aluno seja feita de forma livre, sem a orientação de perguntas específicas fornecidas pelo professor. Espera-se assim dar liberdade à aplicação de experiências e visões dos alunos como filtro à análise dos dados. Esta etapa é importante para que a discussão do caso propicie um momento de trocas de experiências pessoais, ampliando a identificação dos alunos com o dilema proposto pelo caso e fomentando a postura reflexiva sobre as possibilidades pessoais de mudança e ajuste de cada futuro docente.

Recomenda-se que o professor disponibilize um período de 20 a 30 minutos para que os alunos discutam o caso em pequenos grupos antes da discussão plenária. Essa prática não é mandatória, apenas recomendada. Acredita-se que a discussão prévia propicia um enriquecimento da preparação dos alunos, com a troca de impressões e experiências. Serve inclusive como um espaço de expressão mais espontânea, onde os alunos podem relatar experiências pessoais, como docentes, por estarem em ambientes mais privados. Assim, no momento da discussão plenária poderão assumir uma postura mais distanciada de sua própria prática docente, podendo entender o dilema de Cosmo de forma mais neutra.

Para a discussão em grupos, sugerem-se as seguintes questões (assignment questions): Por que Cosmo relata se sentir em uma espécie de "cruzada" pelo método do caso? Quais são as diferenças entre a prática docente de Jorge e Cosmo? Quais são as principais diferenças entre a universidade americana e 
O IESG? O objetivo é fazer uma preparação dos alunos que proporcione a base para seu envolvimento na temática da abertura (método centrado no aluno versus método centrado no professor) e posteriormente para sua participação na discussão plenária.

Vale ressaltar que, em linha com um processo indutivo de aprendizagem, o caso é autossuficiente para análise e não requer leituras ou pesquisas complementares. Entretanto, quando existe uma preferência didática pelo conhecimento prévio dos conceitos teóricos pelos alunos, o caso pode ser acompanhado ou antecedido de leituras prévias que familiarizem o aluno com o funcionamento do método (ERSKINE; LEENDERS; MAUFFETTE-LEENDERS, I998).

\section{ABERTURA DA DISCUSSÃO DO CASO - PLENÁRIA}

A abertura da discussão pode ser usada para facilitar o diagnóstico do caso, mediante as seguintes perguntas: Qual é a diferença entre ensino e aprendizagem? Quais são as vantagens e desvantagens do método de ensino centrado no professor? E do método centrado no aluno?

Com as informações descritas no caso, os alunos podem contribuir na discussão para um delineamento dos territórios metodológicos que constituem o pano de fundo ao dilema de Cosmo: o método centrado no aluno ou no professor. Após esta primeira reflexão, o professor pode fazer a transição para a análise em plenária, ao discutir aspectos típicos ou específicos do professor, aluno e instituição mais adequados para cada estratégia didática. Um exemplo de mapeamento foi apresentado na lâmina I do Plano de discussão plenária (vide Apêndice A).

\section{ANÁLISE DO CASO - PLENÁRIA}

A seguir apresentamos as questões (discussion/transition questions) que podem ser usadas para estimular a análise do caso durante a etapa de discussão em plenária:

1 Que características do corpo docente do IESG dificultam a adoção do método do caso pelo IESG? O que poderia ser feito para mitigar essas barreiras?

2 Pensando no corpo discente de pós-graduação do IESG, onde estão os entraves à adoção mais ampla do método do caso, ou de 
métodos centrados no aluno? Como esses obstáculos poderiam ser suplantados?

3 Apesar de diversas iniciativas, Cosmo percebe que o método do caso ainda não é amplamente adotado na instituição. Que condições, processos e disposições institucionais e culturais do IESG impedem o uso sistemático do método do caso? Que sugestões poderiam ser oferecidas ao IESG?

Questão I - Que características do corpo docente do IESG dificultam a adoção do método do caso pelo IESG? O que poderia ser feito para mitigar essas barreiras?

Cosmo enfrenta no IESG um dilema entre a insistência ou não no método indutivo. Ao comparar o método de Cosmo e de Jorge, vemos uma diferença básica. Enquanto Jorge está preocupado em "cumprir o programa" queé "extenso", apresentando via PowerPoint o maior número de conceitos possível, Cosmo segue uma filosofia de ensino e aprendizagem radicalmente diversa. Para o método do caso, o aprendizado deve ser indutivo, fazendo emergir dos exemplos práticos as conclusões e conceitos junto com a turma.

O papel do professor nos dois tipos de ensino é muito diverso. Enquanto no primeiro, o professor conduz ativa e diretamente os rumos do curso, sendo o principal usuário da palavra, no caso do método indutivo, o papel do professor é mais sutil. Corey (1980) lembra que a influência do professor, no método ativo, está nos elementos menos óbvios como a composição do programa de curso, a seleção do caso e sua posição no semestre, a colocação de perguntas (mais ou menos fechadas) e a coordenação da discussão.

No caso do IESG, as principais barreiras presentes no corpo docente à adoção do método na instituição residem em um processo inercial dos professores, que concentram sua prática docente em aulas expositivas, por entenderem que tem um compromisso com a transmissão de grande carga de conceitos. Além disso, observase certa heterogeneidade no perfil deste grupo, onde alguns conhecem métodos centrados no aluno, e buscam experimentar ainda que limitadamente, e outros que não têm experiência em seu uso. Isso nos leva a concluir que grande parte dos professores carece de uma formação mais consistente, possivelmente não apenas na condução de casos em sala de aula, mas também na redação e confecção de casos. 
Para enfrentar essas barreiras, pode-se sugerir a realização de treinamentos frequentes e diversificados, tratando de diversos temas associados ao método como a aplicação do caso em sala de aula, métodos de avaliação para práticas didáticas centradas no aluno, e a redação de casos. Para que se modifique uma prática culturalmente arraigada, repetida ao longo de anos de experiência docente, é preciso que os professores sejam expostos a discussões frequentes de filosofia e práticas de ensino.

Outra sugestão é a exposição dos professores à experiências de aula com adoção do método do caso, para que possam vivenciar como alunos as vantagens do método. Este tipo de iniciativa se inspira na intenção de oferecer uma experiência com o método, modificando atitudes enraizadas entre os docentes. Por fim, um dos critérios de contratações de futuros professores pode ser a experiência docente com uso do método do caso, trazendo para dentro da instituição novos agentes de mudança, como é o caso de Cosmo.

Questão 2 - Pensando no corpo discente de pós-graduação do IESG, onde estão os entraves à adoção mais ampla do método do caso, ou de métodos centrados no aluno? Como esses obstáculos poderiam ser suplantados?

Os alunos constituem outra dimensão fundamental do sucesso da metodologia. O método ativo só pode funcionar quando os alunos optam por assumir seu papel no espaço de aula. No caso de Cosmo, ele se deparou com uma reação não uniforme. Enquanto alguns alunos mostraram-se animados e envolvidos com o método, outros se mostraram reticentes. Isso é percebido por Cosmo não só pela reação dos alunos em sala, ou pelas pesquisas, mas pela preocupação dos alunos com a correção das tarefas individuais. De uma maneira geral, Cosmo não relatou dificuldades com a participação, leitura ou entrega das análises pelos alunos.

Provavelmente, o hábito de assistir a aulas expositivas gera nos alunos uma experiência familiar com os slides, que passa a ser desafiada por metodologias ativas. Ou seja, os alunos também precisam realizar uma mudança cultural para o método funcionar. Neste caso, surgiu ainda, por exemplo, a situação do aluno tímido, que teme por uma avaliação que prioriza a participação. 
Este exemplo mostra a pouca intimidade com uma proposta pedagógica que coloca o método ativo no centro do desenho do curso.

No caso do IESG, como a maioria do corpo docente não utiliza o método, aqueles que o adotam podem ser mal interpretados. As principais reações a Cosmo vêm de alunos que percebem essa discussão recorrente de casos como perda de tempo, especialmente quando comparam com outros professores que apresentam grande número de conceitos em aulas expositivas. A mudança cultural que pode promover uma predisposição à adoção do método do caso passa pelo treinamento dos alunos, assim como dos professores. No caso dos alunos, um treinamento no início do curso pode ser suficiente, caso o aluno continue sendo exposto ao método ao longo do curso de pós-graduação.

Como lembra Álvaro, alunos e professores já produzem o PCA, que pode servir como plataforma para o desenvolvimento de novos casos de ensino na instituição. Um processo que pode ainda ir além do simples envolvimento dos alunos na redação dos casos: os alunos podem ser convidados para participarem da discussão do mesmo em anos subsequentes, reforçando a cultura do método na instituição.

Questão 3-Apesar de diversas iniciativas, Cosmo percebe que o método do caso ainda não é amplamente adotado na instituição. Que condições, processos e disposições institucionais e culturais do IESG impedem o uso sistemático do método do caso? Que sugestões poderiam ser oferecidas ao IESG?

Por um lado, Cosmo percebe grande vontade da direção em disseminar o método do caso. Grande parte dos dirigentes do IESG vem trabalhando para estimular uma mudança de postura do professor em sala de aula. No entanto, uma das principais dificuldades de Cosmo é a falta de estrutura para o uso do método, especialmente se comparada com a escola americana.

$\mathrm{Na}$ instituição americana, um departamento estava dedicado ao desenvolvimento de casos, bem como à gestão de seu uso pelo corpo docente. Já o IESG contava com a central de casos, que dispunha de uma equipe pequena e uma história recente de mudança de orientação quanto ao uso do caso na instituição. Ao longo de cinco anos aproximadamente o IESG passou 
do uso e desenvolvimento de casos-exemplo, quase jornalísticos, para o estimulo ao desenvolvimento de casos mais abertos, possibilitando o seu uso na discussão em sala. Corey (1980) realça a importância da produção contínua de novos casos para garantir a disponibilidade de material didático para uso dos professores. Apesar da existência da Central de Casos, o repertório de casos a disposição do corpo docente ainda era reduzido e ninguém controlava seu uso para evitar o uso repetido em diferentes disciplinas. Além disso, os formatos dos casos publicados na Central de Casos eram variados (nem todos correspondendo às exigências mínimas do método) e poucos possuíam notas de ensino.

Outro aspecto relevante refere-se às estruturas físicas de sala de aula. Erskine, Leenders e Mauffette-Leenders (1998) apresentam uma série de recomendações para o bom funcionamento do método do caso, discutindo o desenho ideal de sala para propiciar um debate não centrado na figura do professor. No caso do IESG, a sala estava estruturada no formato adequado para palestras, com as cadeiras fixas e voltadas para um pequeno quadro branco. Era muito difícil alterar a disposição dos alunos para adaptar-se às condições recomendadas para o método. Além disso, a instituição não contava com salas de apoio para discussões em grupo.

Como possível solução para turmas menores, os professores poderiam pensar em fazer a discussão de pequenos grupos na própria sala de aula. Outra ideia pode ser a construção ou adaptação de uma sala que sirva como piloto à experimentação do método na instituição, podendo ser reservada aos professores que se voluntariem a adotar o método mais amplamente. Ademais, o tamanho inadequado do quadro branco poderia ser compensado pela adição de flip chart para apoiar a discussão em aula.

A identificação dos alunos é uma dimensão importante do uso do método do caso pela necessidade de avaliação da participação pelos professores. Erskine, Leenders e Mauffette-Leenders (1998) vão sugerir o uso de etiquetas, crachás ou plaquinhas para garantir a fácil identificação e memorização de nomes dos alunos. No caso do IESG, as mesas inclinadas impedem a colocação de plaquinhas. Cosmo soluciona essa questão com o mapa da sala, que facilita o controle dos nomes para atribuir notas de participação. 
Alguns aspectos, no entanto, facilitam a aplicação do método do caso no IESG. A secretaria de professores funcionava com presteza e entregava com antecedência todo o material aos alunos.

\section{ENCERRAMENTO DA DISCUSSÃO - PLENÁRIA}

O encerramento poderia ser usado para a construção conjunta de uma agenda de iniciativas institucionais (plano de ação) para favorecer o processo de implantação plena do método do caso no IESG. Assim, sugere-se a seguinte questão para o debate final: $\mathrm{O}$ que poderia ser feito para viabilizar a adoção do método do caso no IESG?

As soluções para instalação de um ambiente e uma cultura propícios à adoção mais ampla do método podem se organizar em torno de dois eixos: o público (IESG - instituição) e o privado (Cosmo - professor). Ou seja, ações pertinentes à instância institucional, sob a responsabilidade de seus dirigentes, e ações específicas à esfera de atuação do professor.

Espera-se, portanto, que surjam contribuições dos alunos endereçando diferentes níveis do plano de ação institucional (IESG), como por exemplo: (a) restruturação da Central de Casos como motor da geração de matéria prima para a prática didática centrada em casos; (b) treinamento e acompanhamento contínuo do grupo de docentes; (c) formalização do controle do uso de casos pelas chefias de área, evitando a impressão de repetição de material pelos alunos; (d) oferta de uma disciplina sobre o papel do aluno no método do caso, a ser cursada no início de cada programa de pós-graduação; e outras tantas iniciativas.

Nessa etapa da discussão deve ficar evidente aos alunos que todas essas iniciativas podem ser necessárias, todavia, não suficientes para garantir a plena e pacífica adoção do método do caso no IESG. O que faltaria, então? O que se pode dizer sobre o papel a ser desempenhado pelo quadro docente, tanto como um todo, quanto individualmente? O que se pode esperar dos Cosmos e do Jorge? Em que medida as escolhas individuais de cada docente podem se transformar em pontes ou paredes à implantação do método? 


\section{O QUE OCORREU DEPOIS DO CASO}

O professor Cosmo é uma personagem de ficção dentro de um contexto real. Mas representa a intenção e esforço de vários professores dentro do IESG atualmente. Após a redação do caso, verificamos algumas soluções individuais, dadas por professores para a aplicação do método do caso na instituição. É interessante observar esses exemplos para obter pistas de uma possível adaptação da metodologia à realidade do IESG, onde professores podem utilizar o caso mesmo sem ter à sua disposição toda a estrutura que tradicionalmente se dispõe nas escolas que usam o método de forma mais ortodoxa.

Um dos professores entrevistados utiliza quatro casos ao longo de cursos de onze encontros. Ele alterna duas aulas expositivas com uma aula inteiramente dedicada à discussão de um caso. Para essa aula, os alunos devem trazer a preparação individual por escrito, e este documento fará parte de sua avaliação final. Ele eliminou a discussão em pequenos grupos, a não ser que a turma seja pequena e ele possa então utilizar o espaço da sala de aula para acomodar os grupos confortavelmente. Segundo este professor, sua motivação para tal adaptação se justifica na curta duração das aulas que não permitem cobrir a discussão do caso de forma completa e aprofundada, seguindo todo o ciclo do método, e a apresentação dos conceitos do programa.

Outro professor entrevistado utiliza o caso aberto apenas na última aula, como recurso de fechamento do curso. Sua justificativa é a baixa instrumentalização dos alunos e o tempo reduzido dos encontros que impedem uma discussão aprofundada como preconiza o método do caso. Ambos utilizam a preparação individual como documento de avaliação, garantindo assim uma preparação de maior qualidade para as discussões.

Do ponto de vista institucional, o IESG realiza regularmente treinamentos sobre o método do caso para seus professores, inclusive convidando especialistas de outras instituições. Além disso, vem revendo os protocolos da central de casos, padronizando os materiais recebidos e garantindo maior qualidade e densidade à produção gerada. 


\section{REFLEXÃO FINAL}

O caso objetiva contribuir para um debate ainda muito frágil no campo do ensino em Administração que é a adoção de formas mais dinâmicas e interativas de ensino em nossas salas de aula. O ensino tradicional, centrado no professor, como o emissor de informações e conhecimento, fica cada vez mais ultrapassado diante do novo perfil dos discentes, mais questionadores e autônomos. No entanto, a maioria dos alunos e professores tipicamente foi submetida a um método expositivo de aprendizagem e podem não compreender a proposta trazida pelo método do caso. Assim, idealmente, a condução da discussão desse caso exige do professor um prévio conhecimento dessa metodologia. A seguir apresentamos uma lista de referências bibliográficas que visa apresentar e aprofundar o conhecimento sobre o método, de forma a instrumentalizar o docente, evitando-se dessa forma que a discussão se torne estéril. 


\section{BIBLIOGRAFIA DE APOIO RECOMENDADA}

CHRISTENSEN, C.R. Every student teaches and every teacher learns: the reciprocal gift of discussion teaching. In: CHRISTENSEN, C.R.; GARVIN, D.; SWEET, A. (Eds.). Education for Judgment: the artistry of discussion leadership. Boston: Harvard Business School Press, 1991.

LLANO CIFUENTES, C. El método del caso y el desarrollo de las capacidades activas. México: IPADE, 1977. FHN-15.

MAUFFETTE-LEENDERS, L.; ERSKINE, J.; LEENDERS, M. R. Learning with cases. Canada: Ivey Publishing, 1997.

RANGAN, V. K. Choreographing a case class. Boston: Harvard Business School Publishing, 1996.

ROESCH, S. A construção de casos em gestão social: diferenças entre estudo de caso e casos de ensino. In: FISCHER, T.; ROESCH, S.; MELO, V. Paternostro. Gestão do desenvolvimento territorial e residência social. Bahia: CIAGS/UFBA, 2006.

WEBER, M.M.; KIRK, D.J. Teaching teachers to teach cases: it's not what you know, it's what you ask. Marketing Education Review, v. 10, n. 2, p. 1-24, 2000.

Referências

COREY, E. R. Case method teaching. Harvard Business School Case, Nov. 1980.

ERSKINE, J.; LEENDERS, M.R.; MAUFFETTE-LEENDERS, L.A. Teaching with cases. London: Ivey Publishing, 1998.

HEATH, J. Teaching and Writing Case Studies: A practical guide. 3.ed. Cranfield/UK: $\mathrm{ECCH}, 2006$. 
APÊNDICE A PLANO DE DISCUSSÃO (ESQUEMA PROPOSTO PARA O QUADRO)
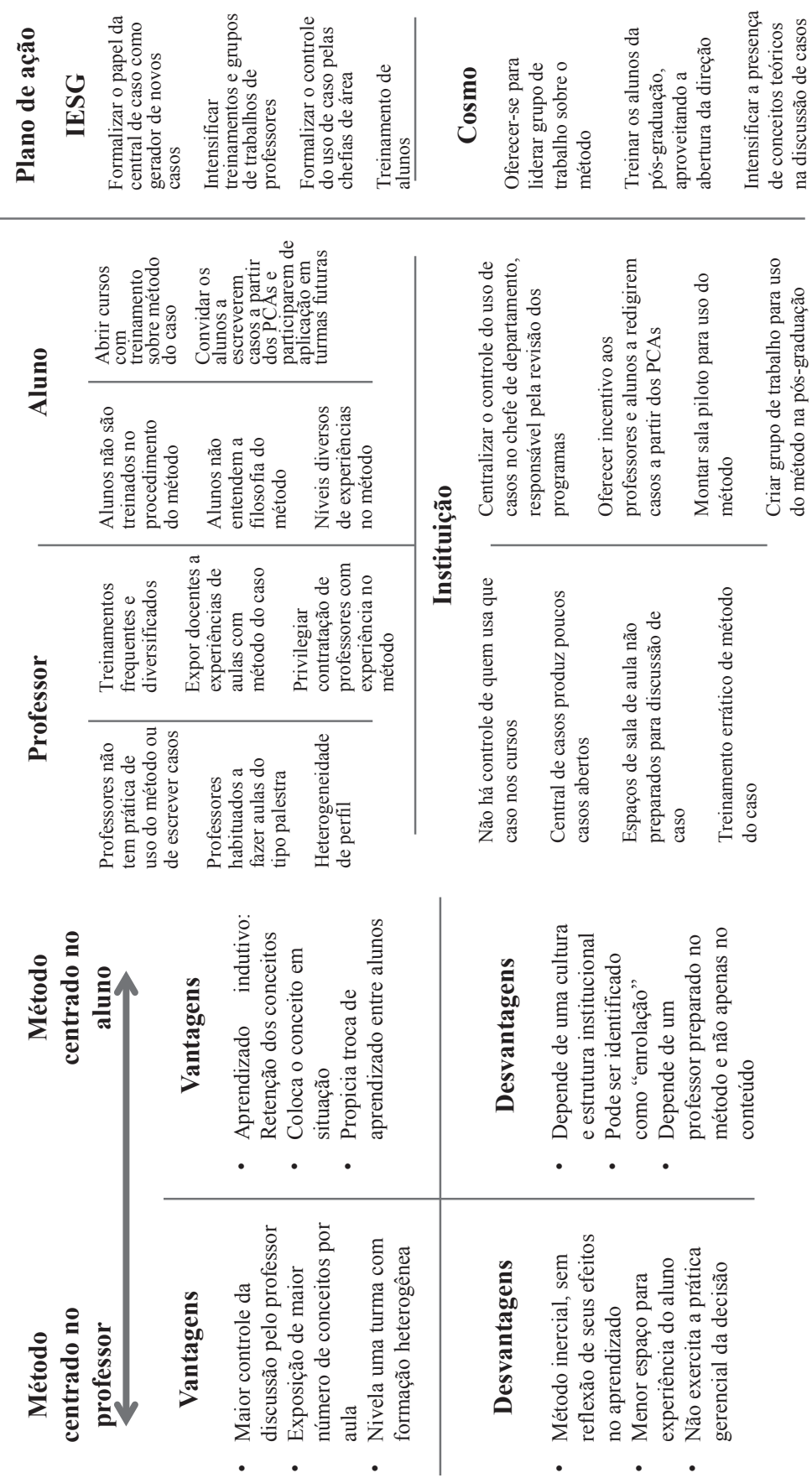


\section{DADOS DOS AUTORES}

ROBERTA DIAS CAMPOS ${ }^{\star}$ roberta.campos@coppead.ufrj.br

Doutora em Administração pela CoPPEAD-UFRJ

e em Ciências Sociais pela Paris Descartes

Descartes e em Ciências Sociais por Paris Descartes

Instituição de vinculação: Universidade Federal do Rio de Janeiro - Instituto

COPPEAD de Administração

Rio de Janeiro/RJ - Brasil

Áreas de interesse em pesquisa: Marketing, Comportamento do Consumidor e Cultura.

^Rua Pascoal Lemme, 355 Ilha do Fundão Rio de Janeiro/RJ 21941-918

VICTOR MANOEL CUNHA DE ALMEIDA valmeida@coppead.ufrj.br Doutor em Administração pelo COPPEAD/UFRJ

Instituição de vinculação atual: Universidade Federal do Rio de Janeiro - Instituto COPPEAD de Administração

Rio de Janeiro/RJ - Brasil

Áreas de interesse em pesquisa: Marketing, Comportamento do Consumidor e Método do Caso. 